doi:10.12662/2359-618xregea.v9i2.p186-199.2020

\author{
CASOS DE ENSINO
}

\title{
A INSERÇÃO DA EDUCAÇÃO AMBIENTAL E DA GESTÃO AMBIENTAL NO CURSO DE ADMINISTRAÇÃO
}

\author{
THE ENVIRONMENTAL EDUCATION AND \\ ENVIRONMENTAL MANAGEMENT INSERTION IN \\ THE BUSINESS COURSE
}

\section{RESUMO}

Este caso de ensino trata da possibilidade de inserção dos temas educação ambiental e gestão ambiental em uma faculdade de Administração no interior de Minas Gerais. Roberta, professora efetiva da instituição, começou a pesquisar acerca da sustentabilidade desde a sua passagem pelo doutorado. Desde então, dedicou parte significativa de seu tempo para pesquisar o desenvolvimento sustentável nas organizações. Ao chegar à universidade, uniu-se a um grupo de professores os quais desenvolviam pesquisas nessa área. Por meio de um diagnóstico feito na unidade sobre o ensino de administração e sua relação com as temáticas ambientais, identifica-

Vivian Duarte Couto Fernandes vivian@ufu.br Doutora em Ciências Contábeis. Mestre em Administração. Professora assistente da Universidade Federal de Uberlândia. Universidade Federal de Uberlândia. Uberlândia $-M G-B R$.

Etienne Cardoso Abdala etienne@ufu.br Doutora em Administração de Empresas. Professora na Universidade Federal de Uberlândia. Universidade Federal de Uberlândia. Uberlândia $-M G-B R$.

Luciana Oranges Cezarino cezarino@ufu.br Doutora em Administração. Professora na Universidade Federal de Uberlândia. Universidade Federal de Uberlândia. Uberlândia $-M G$ $-B R$. ram uma lacuna expressiva entre a realidade e a prática. Assim, o grupo de pesquisadores reavaliou o ensino, a pesquisa e a extensão de modo que a educação ambiental e o estudo da gestão ambiental nas organizações fossem inseridos no curso de Administração.

Palavras-chave: Educação Ambiental. Gestão Ambiental. Ensino de Administração.

\begin{abstract}
This teaching case deals with the possibility of inserting environmental education and environmental management topics into a business school in the countryside of Minas Gerais. Roberta, an effective professor at the institution, has started researching sustainability since her doctorate. Since then she has devoted a significant part of her time to research sustainable development in organizations. Upon arriving at the university she joined a group of professors who were developing research in this area. Based on a diagnosis made in the business school on the relationship between teaching and environmental issues, they identified a significant gap between reality and practice. Thus, the group of researchers re-evaluated teaching, research and extension so that environmen-
\end{abstract}


tal education and the study of environmental management in organizations were included in the business course.

Keywords: Environmental Education. Environmental Management. Management Education.

\section{INTRODUÇÃO}

A preocupação com o meio ambiente começou a partir do século XX, quando estudos apontavam para um desastre ambiental caso as estruturas de produção não sofressem alterações rapidamente. Em meados da década de 1970, a questão ambiental passa a ser tratada como um problema da sociedade, que precisa ser discutido para que não seja ameaçada a vida no planeta em longo prazo.

A institucionalização da Educação Ambiental no ensino superior, promovendo tanto a produção do conhecimento quanto a formação de pessoal especializado em suas áreas afins, são prioridades da Política Nacional de Educação Ambiental, de responsabilidade do Ministério da Educação. Pesquisas sobre o tema Sustentabilidade na Educação Superior são recentes conforme apontam Rohrich e Takahashl (2019). As autoras destacam o desenvolvimento do Principles for Responsible Management Education (PRME), em 2007, pelas Nações Unidas como uma questão marcante para a educação sustentável, além do fato de que o editorial publicado na International Journal of Sustainability in Higher Education indica a importância da divulgação e a publicação de pesquisas e estudos sobre o tema nas Instituições de Ensino Superior.

Conforme afirmam Findler et al. (2019), embora existam publicações em educação sustentável no ensino superior, e essas pesquisas tenham melhorado o entendimento sobre o que as universidades podem fazer pela busca do desenvolvimento sustentável, pouco se sabe sobre o que eles realmente alcançam com suas diversas atividades para sociedade, para o ambiente natural e para a economia, ou seja, ainda não está claro qual o impacto que essas ações têm sobre o desenvolvimento sustentável.

Ladeira, Santini e Araújo (2012) já argu- mentavam que, devido à necessidade de maior conscientização a respeito de práticas sustentáveis, as Instituições de Ensino também passaram a considerar o assunto com maior relevância. No entanto, questionam em seu estudo se, necessariamente, os estudantes conseguem perceber tal importância a ponto de se conscientizarem, evidenciando a possibilidade de haver vários níveis de conscientização por parte dos atores presentes nessas Instituições.

Contudo, embora não se possa afirmar que a oferta do ensino resultará em pessoas mais responsáveis quanto às práticas de sustentabilidade nas organizações (LADEIRA; SANTINI; ARAUJO, 2012), não há dúvidas de que as instituições precisam incluir na dinâmica de seus cursos de graduação a discussão sobre a gestão sustentável, o consumo sustentável e o desenvolvimento sustentável. É com esse entendimento que o caso de ensino desenvolvido nesta pesquisa tem como propósito estimular o debate nos cursos de graduação na área de gestão. A história de Roberta exemplifica a realidade de muitos cursos no Brasil, em que o tema sustentabilidade é trabalhado pontualmente, em disciplinas isoladas ou projetos específicos.

Nesse sentido, a formação de profissionais, em especial para este caso, do curso de Administração, deve passar pela discussão de sustentabilidade nas organizações de forma transversal e sistêmica. Para tanto, propõe-se a inserção de temáticas de gestão ambiental nas organizações em suas mais diversas áreas, como gestão de pessoas, produção, operações, finanças e marketing, de forma integrada.

Para a construção desse caso, uma pesquisa qualitativa foi desenhada, com coleta de dados em uma instituição de ensino superior por meio de observação direta, questionários aos estudantes, e documentos públicos da instituição. Para a escrita do caso, foram inseridos dados reais e alguns dados fictícios, para que pudessem dar mais subsídio para os professores em sua utilização. Os nomes utilizados na pesquisa são fictícios.

Espera-se que a utilização deste caso possa contribuir para a formação de estudantes mais críticos, com vistas à mudança de comportamento e de atitude, além de gerar um ambiente de 
construção e reconstrução de novas respostas para o futuro das organizações, respeitando sua diversidade e atento aos impactos de suas ações. Jacobi, Raufflet e Arruda (2011) já destacavam a necessidade de se contribuir para a disseminação de experiências e práticas educativas nos cursos de graduação, para a formação dos estudantes.

\section{O CASO}

A professora Roberta ingressou, em 2013, como professora efetiva na Faculdade do Interior de Minas Gerais. Sua trajetória acadêmica a conduziu para o desenvolvimento de pesquisas na área de sustentabilidade, tendo realizado seu doutorado com foco na educação do ensino superior. Com uma experiência internacional em que a pauta ambiental era latente, suas pesquisas estavam voltadas para o melhoramento da eficiência da gestão ambiental das organizações, visto que as preocupações com o desenvolvimento sustentável passaram a ser significativas em sua concepção de mundo.

Assim que conheceu toda a estrutura da faculdade, Roberta descobriu que alguns professores estavam reunindo-se para consolidar um grupo de pesquisa em Gestão Ambiental, e, assim, uniu-se a eles. O grupo era composto por mais três professores do curso: um da área de organizações e estratégia, outro da área de gestão de pessoas e uma da área de finanças, além de Roberta, da área de operações. Era um grupo heterogêneo com um desejo comum.

No início de suas atividades, o grupo percebeu a necessidade de um diagnóstico do ensino de administração de sua faculdade para entender como estava tanto o entendimento dos estudantes em relação à temática da sustentabilidade, quanto à participação e envolvimento dos docentes para o ensino de gestão ambiental dentro de suas áreas específicas.

\subsection{O DIAGNÓSTICO}

Para a realização do diagnóstico da unidade, os professores se uniram e, com a ajuda de alguns estudantes, elaboraram um plano de atividades que contemplava o levantamento de informações nas três dimensões: ensino, pesquisa e extensão. Em relação ao ensino, foi feita uma busca em todas as fichas de disciplinas dos cursos oferecidos pela faculdade com o objetivo de elencar aquelas que abordavam a sustentabilidade em sua ementa. O quadro 1 mostra os resultados.

Quadro 1 - Disciplinas ministradas com conteúdo sobre sustentabilidade

\begin{tabular}{|c|c|c|}
\hline Curso & Nome disciplina & Como o tema é tratado \\
\hline \multirow{7}{*}{ Administração } & $\begin{array}{l}\text { Organizações e } \\
\text { Sociedade }^{1,3}\end{array}$ & $\begin{array}{l}\text { Aborda uma visão geral dos problemas e desafios ambientais e o papel } \\
\text { das organizações na produção e solução dos problemas ambientais. }\end{array}$ \\
\hline & $\begin{array}{l}\text { Ética em } \\
\text { Organizações }\end{array}$ & $\begin{array}{l}\text { Diante dos dilemas éticos que permeiam as relações profissionais } \\
\text { e o processo decisório, a disciplina promove a reflexão dos } \\
\text { estudantes sobre possíveis impactos ambientais decorrentes das } \\
\text { ações dos gestores das organizações. }\end{array}$ \\
\hline & $\begin{array}{l}\text { Comportamento do } \\
\text { Consumidor } \\
\text { 1,3 }\end{array}$ & $\begin{array}{l}\text { Aborda a questão do descarte dos produtos e das embalagens após } \\
\text { o consumo e os impactos gerados ao meio ambiente. }\end{array}$ \\
\hline & $\begin{array}{l}\text { Logística e Cadeia } \\
\text { de Suprimentos }{ }^{1,5}\end{array}$ & $\begin{array}{l}\text { Capacita o estudante na tomada de decisão referente à identificação dos } \\
\text { suprimentos necessários, à seleção dos fornecedores, à gestão integrada dos } \\
\text { estoques de materiais, de processamentos e de produtos e ou serviços finais. } \\
\text { Aborda, também, as características da embalagem e logística reversa. }\end{array}$ \\
\hline & $\begin{array}{l}\text { Gestão Social e } \\
\text { Sustentabilidade }{ }^{2,6}\end{array}$ & $\begin{array}{l}\text { Temas gerais que relacionam a temática ambiental dentro das } \\
\text { organizações do terceiro setor. }\end{array}$ \\
\hline & Gestão Ambiental ${ }^{2,6}$ & $\begin{array}{l}\text { Faz uma abordagem histórica do conceito de gestão ambiental e } \\
\text { trata de temas gerais de gestão ambiental nas organizações. }\end{array}$ \\
\hline & $\begin{array}{l}\text { Sustentabilidade em } \\
\text { Produção e Operações }\end{array}$ & $\begin{array}{l}\text { Temas gerais que relacionam a sustentabilidade dentro das } \\
\text { organizações, na área específica de produção/operações. }\end{array}$ \\
\hline
\end{tabular}




\begin{tabular}{|c|l|l|}
$\begin{array}{c}\text { Gestão da } \\
\text { Informação }\end{array}$ & $\begin{array}{l}\text { Comportamento do } \\
\text { Consumidor }{ }^{1,5}\end{array}$ & $\begin{array}{l}\text { Temas ligados ao descarte e meio ambiente, que estão localizados } \\
\text { no processo pós-compra. }\end{array}$ \\
& $\begin{array}{l}\text { Modelo de } \\
\text { Negócios }\end{array}$ & $\begin{array}{l}\text { Traz os conceitos relacionados aos negócios verdes e o papel da } \\
\text { tecnologia da informação, envolvendo a ecoeficiência nas cidades } \\
\text { e nos negócios. }\end{array}$ \\
\hline $\begin{array}{c}\text { Adratam da evolução da gestão ambiental, as políticas de comando } \\
\text { Pública }\end{array}$ & $\begin{array}{l}\text { Gestão Ambiental e e } \\
\text { e controle, e os conceitos e propostas de um desenvolvimento } \\
\text { Sustentável. A disciplina aborda ainda o papel dos municípios, } \\
\text { estados e União, com foco na Agenda Ambiental da Administração } \\
\text { Pública e as políticas do governo brasileiro perante os acordos } \\
\text { internacionais de proteção ambiental. }\end{array}$ \\
\hline
\end{tabular}

${ }^{1}$ Disciplinas obrigatórias; ${ }^{2}$ Disciplinas optativas; ${ }^{3}$ Lecionadas no segundo período do curso; ${ }^{4}$ Lecionadas no quarto período do curso; ${ }^{5}$ Lecionadas no sexto período do curso; ${ }^{6}$ Lecionadas a partir do sexto período do curso.

Fonte: elaboração própria.

O grupo identificou que as disciplinas que tratam a sustentabilidade com maior profundidade e de maneira mais diversa são caracterizadas como 'optativas' e apenas uma aborda a educação ambiental. Entre todas as disciplinas, apenas três são totalmente voltadas ao tema, sendo uma ministrada pela área de Organizações e Estratégia e duas ministradas pela área de Operações.

Em relação ao diagnóstico da pesquisa e extensão, foi feito um levantamento sobre todas as atividades realizadas e em andamento na faculdade, que abordavam as questões relacionadas à sustentabilidade. Para tanto, fez-se uma busca minuciosa em todos os currículos dos professores da unidade. O gráfico 1 mostra a soma total do número de publicações dos professores entre os anos de 2009 e 2014.
O que chamou a atenção do grupo, nesses dados, foi que a maioria das publicações sobre o tema estava concentrada nas pesquisas de professores das áreas de Organizações e Estratégia, e Operações e Sistemas, com pequenas contribuições das demais áreas da unidade. O quadro 2 mostra a relação de projetos de pesquisas realizados desde 2009 pelos docentes da faculdade. A maioria deles envolve estudos sobre reciclagem de lixo, fatores críticos do desenvolvimento social, econômico e ambiental local, trabalho escravo, responsabilidade social, projetos e ações socioambientais, economia solidária, empreendimentos sociais, cidadania em projetos sociais, projeto socioambiental, práticas ambientais das indústrias, gestão de resíduos sólidos e logística reversa.

Gráfico 1- Quantidade de publicações relacionadas à sustentabilidade

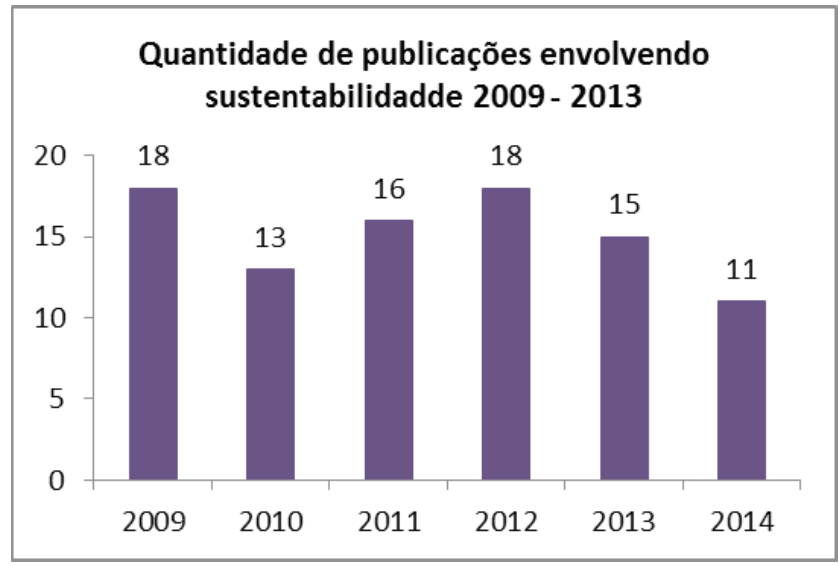

Fonte: elaboração própria. 
Quadro 2 - Projetos de Pesquisas desenvolvidos pela unidade acadêmica

\begin{tabular}{|c|c|}
\hline Docente & Projeto \\
\hline \multirow{2}{*}{ Professor A } & Pesquisa sobre reciclagem de lixo na cidade $\mathrm{X}$ \\
\hline & Cartilha de ética empresarial \\
\hline \multirow{2}{*}{ Professor B } & Fatores críticos de sucesso que influenciam o desenvolvimento sustentável do distrito Y \\
\hline & Investigação quantitativa sobre as oscilações de preço do etanol e açúcar \\
\hline Professor C & Identificação dos determinantes do trabalho infantil em 3 estados brasileiros \\
\hline \multirow{2}{*}{ Professor D } & A influência da Responsabilidade Sócio-empresarial na decisão de compra do estudante \\
\hline & Avaliação de um projeto sócio ambiental no distrito $\mathrm{Z}$ \\
\hline \multirow{3}{*}{ Professor E } & $\begin{array}{l}\text { Processos de incubação de empreendimentos econômicos solidários na perspectiva da } \\
\text { extensão universitária }\end{array}$ \\
\hline & $\begin{array}{l}\text { Empreendimentos e mercados solidários: aplicação dos princípios de Administração } \\
\text { Mercadológica }\end{array}$ \\
\hline & Incubação de empreendimentos populares solidários: o caso de uma associação na cidade $\mathrm{R}$ \\
\hline Professor F & Estudo do perfil dos empreendedores sociais na cidade $\mathrm{W}$ \\
\hline Professor G & A prática da cidadania em projetos sociais \\
\hline Professor $\mathrm{H}$ & Avaliação dos resultados de um projeto socioambiental no distrito $\mathrm{P}$ \\
\hline Professor I & Acesso dos operadores de serviços de saneamento básico às fontes de recursos financeiros \\
\hline \multirow{3}{*}{ Professor J } & Evidências de práticas ambientais das indústrias da cidade $\mathrm{S}$ \\
\hline & A logística reversa no contexto de computadores e notebooks \\
\hline & Gestão de resíduos sólidos: as práticas da logística reversa de pneumáticos \\
\hline \multirow{2}{*}{ Professor K } & Projeto GOLDEN for Sustainability \\
\hline & Projeto PRME - Principles of Responsible Management Education \\
\hline Professor L & Estratégia e Sustentabilidade \\
\hline \multirow{4}{*}{$\begin{array}{l}\text { Professor } \\
\quad \mathrm{M}\end{array}$} & Hortas comunitárias: educação e sustentabilidade \\
\hline & Capacitação de produtoras num empreendimento social \\
\hline & Ampliação e comercialização de brinquedos artesanais \\
\hline & Implantação de um desenvolvimento territorial por meio de arranjos socioprodutivos \\
\hline Professor N & Oficina de brinquedos para integração social \\
\hline Professor O & Inteligência competitiva e cooperação entre arranjos produtivos locais \\
\hline
\end{tabular}

Fonte: elaboração própria.

O professor da área de Organizações e Estratégia, Pedro, questionou:

"- Acho que a faculdade está muito bem nas suas atividades. Acredito que estamos bem na inserção da sustentabilidade nos nossos cursos. Vejam a quantidade de pesquisas e publicações!"

“- Mas elas estão dispersas nos anos. Não temos uma pesquisa constante. Os dados variam muito de ano a ano. - Retrucou Carla, a professora de finanças."
“- Eu concordo com você, Carla. Além disso, podemos perceber que as pesquisas estão concentradas em áreas específicas do curso. Na nossa área de Gestão de Pessoas, quase não temos projetos". - Disse Cláudio, um pouco intrigado.

"- Então, talvez vocês não estejam fazendo a parte de vocês". - Provocou Pedro, que fazia parte da área com mais pesquisas e publicações sobre o tema.

Roberta fez logo uma proposta: "Eu 
acho que falta uma coisa no nosso diagnóstico. Precisamos consultar os estudantes também." Pedro questionou: "Como assim?".

"- Precisamos saber se as nossas pesquisas, o ensino e os projetos estão atingindo os nossos estudantes. É preciso identificar como isso se reflete no conhecimento adquirido pelos nossos clientes!"

Todos concordaram e acharam que era necessário investigar melhor o quanto sabiam os estudantes daquela faculdade sobre o tema sustentabilidade, em suas várias dimensões. Para tanto, utilizaram o teste PRME de conhecimento em sustentabilidade (CEZARINO et al., 2018) que foi amplamente aplicado. O quadro 3 mostra os resultados deste levantamento. precisa promover a educação ambiental e o debate extensivo sobre gestão ambiental dentro das organizações. Além disso, é preciso promover atividades de pesquisa e extensão sobre o assunto, para que o estudante tenha um entendimento prático de como esses conceitos são aplicados dentro do ambiente organizacional. O desafio é propor uma abordagem mais sistêmica que agregue a dimensão da sustentabilidade em suas disciplinas e em projetos integrados.

\section{NOTAS DE ENSINO}

A instituição de ensino superior em que esta pesquisa foi realizada, aqui denominada Faculdade do Interior de Minas Gerais, é uma

Quadro 3 - Conhecimento dos alunos em relação ao tema sustentabilidade

\begin{tabular}{|c|c|c|c|}
\hline Tema & $\begin{array}{l}\text { Média de } \\
\text { acertos }\end{array}$ & $\begin{array}{l}\text { Menor } \% \\
\text { de acertos }\end{array}$ & $\begin{array}{l}\text { Maior } \% \\
\text { de acertos }\end{array}$ \\
\hline Princípios norteadores do desenvolvimento sustentável & $51 \%$ & $18 \%$ & $91 \%$ \\
\hline Fator ambiental: tendências e questões-chave no contexto local e global & $50 \%$ & $10 \%$ & $90 \%$ \\
\hline Fator social: tendências e questões-chave no contexto local e global & $38 \%$ & $0 \%$ & $83 \%$ \\
\hline Fator econômico: tendências e questões-chave no contexto local e global & $53 \%$ & $11 \%$ & $100 \%$ \\
\hline Governança organizacional & $34 \%$ & $0 \%$ & $100 \%$ \\
\hline $\begin{array}{l}\text { Direitos humanos \& envolvimento e desenvolvimento da } \\
\text { sociedade }\end{array}$ & $48 \%$ & $13 \%$ & $85 \%$ \\
\hline Meio ambiente & $54 \%$ & $20 \%$ & $100 \%$ \\
\hline $\begin{array}{l}\text { Práticas operacionais justas \& práticas trabalhistas \& questões de } \\
\text { consumo }\end{array}$ & $53 \%$ & $12 \%$ & $88 \%$ \\
\hline
\end{tabular}

Fonte: elaboração própria a partir de dados da pesquisa.

Assim, o grupo de pesquisa em Gestão Ambiental decidiu que era hora de rever os planos de ensino e a própria ementa do curso, a fim de inserir a educação ambiental como norteadora do debate central. Como se tratava de cursos na área de negócios, era urgente fazer a discussão da gestão ambiental nas organizações nas diversas áreas de conhecimento dos estudantes: marketing, operações, finanças, gestão de pessoas, estratégia.

Você fará parte desta equipe de professores e estudantes. A faculdade precisa reestruturar a forma de abordagem do tema sustentabilidade dentro de seu curso de graduação. Para tanto, ela das importantes universidades do interior do estado. As informações utilizadas como fonte de dados empíricos foram obtidas por meio de (1) uma pesquisa documental nos arquivos oficiais da organização, (2) observação direta nas atividades desenvolvidas pela Instituição, (3) pesquisa documental nos Lattes dos professores da unidade; e, (4) levantamento de informação junto a seus estudantes, mediante questionário.

Para a pesquisa documental, foram levantados todos os projetos de pesquisa e extensão desenvolvidos no âmbito da faculdade, além de documentos fundacionais como o projeto pedagógico do curso e as fichas de disciplinas. A 
observação direta foi importante para se compreender como a discussão da sustentabilidade é tratada nas instâncias de decisão dos conselhos e comissões. A pesquisa documental nos currículos dos professores efetivos que lecionam nesta faculdade foi importante para captar alguma pesquisa ou atividade que estava sendo desenvolvida por eles, em outras unidades acadêmicas ou em projetos que não constavam nos documentos oficiais da Instituição. Por fim, a aplicação de questionário aos estudantes permitiu conhecer o seu nível de conhecimento acerca do tema sustentabilidade (CEZARINO et al., 2018). Os dados foram coletados no ano de 2015.

\subsection{OBJETIVOS EDUCACIONAIS}

O caso em questão tem por objetivos educacionais dois elementos. O primeiro deles, sob o ponto de vista cognitivo, tem como proposta:

a) promover a análise de problemas, propor e indagar decisões em relação à educação ambiental no ensino superior;

b) estimular a reflexão entre a teoria de gestão de ambiental nas organizações e a forma como ela deve ser apresentada dentro de sala de aula nas diversas áreas do conhecimento da administração;

c) ampliar a capacidade de relacionar a discussão sobre sustentabilidade e a sua aplicação no contexto organizacional.

O segundo elemento versa sobre o ponto de vista comportamental, pois permite que estudantes e professores se utilizem desse instrumento para propor diálogos e discussões saudáveis de modo que haja respeito mútuo às opiniões e às ideias divergentes, permitindo que cada participante possa expor seus pontos de vista sem retaliação.

\subsection{UTILIZAÇÃO DO CASO}

Este caso deve ser utilizado com estudantes de graduação de cursos na área de Gestão e Negócios, em diferentes disciplinas, nas diversas áreas do conhecimento, visto que a discussão perpassa todo o contexto do curso.
No entanto, sugere-se que a aplicação seja feita em disciplinas mais adiantadas do curso, visto que os estudantes deverão propor a inserção do tema sustentabilidade de maneira transversal e integrada com todas as áreas: finanças, marketing, operações, gestão de pessoas, etc.

Este caso permite que o professor explore três focos de estudos. O primeiro deles versa sobre a educação ambiental. Nesse caso, o objetivo deve ser a discussão de como promover o conhecimento dos estudantes da área de negócios em educação ambiental, seguindo as orientações da Política Nacional de Educação Ambiental promovida pelo Ministério da Educação. O professor deverá apresentar a Lei 9.795, de 27 de abril de 1999, e a Proposta de Diretrizes Curriculares Nacionais para a Educação Ambiental como subsídio para o debate. Para esse objetivo, o professor poderá propor um debate coletivo, separando os estudantes em grupos de discussões em que cada um deles apresentará suas propostas.

O segundo foco de estudos gira em torno da Gestão Ambiental dentro das Organizações. Para tanto, a discussão deve permear os debates teóricos a partir de Jabbour e Jabbour (2013), evidenciando as principais questões que envolvem o tema. O professor poderá dividir a sala em grupos de estudantes, e cada grupo ficará responsável por apresentar a proposta de uma área específica da administração, lembrando-se da necessidade de integração entre as áreas. Então o grupo 1 fará uma discussão sobre a gestão ambiental dentro da área de operações da empresa; o grupo 2 discutirá a gestão ambiental para a área de marketing, e assim por diante.

O terceiro foco de estudos, que é mais completo, deverá, a partir das diretrizes do plano nacional de educação ambiental, fomentar as discussões acerca da gestão ambiental nas organizações, ou seja, é uma abordagem dos dois tópicos anteriores. Para isso, o professor poderá dividir em dois momentos a discussão, fazendo as etapas anteriormente citadas, uma após a outra. Assim, utilizará o caso para discutir tanto a educação ambiental quanto a sua aplicação na administração das organizações. 


\subsection{QUESTÕES PARA DISCUSSÃO}

Para que o professor possa aplicar o caso de ensino descrito, sugerem-se as seguintes questões:

a) é possível dizer que a faculdade em análise aborda a temática da sustentabilidade de forma adequada? Que fatores apresentados justificam sua resposta? Analisar a Política Nacional de Educação Ambiental, as Diretrizes Curriculares Nacionais para a Educação Ambiental, e relacionar com as Diretrizes Curriculares Nacionais do Curso de Administração;

b) o desenvolvimento sustentável prevê um equilíbrio entre as dimensões econômica, social e ambiental em qualquer área de atuação. Pode-se dizer que as atividades e pesquisas realizadas pelos professores da faculdade contemplam essas dimensões? Discutir o conceito de sustentabilidade a partir do conceito de Elkington (2001): Triple Bottom Line;

c) de acordo com a Carta de Belgrado, quais devem ser as diretrizes dos Programas De Educação Ambiental? Como poderiam ser introduzidos esses objetivos no curso de Administração?;

d) segundo Jabbour e Jabbour (2013), é possível promover a gestão ambiental em seu estágio proativo nas organizações, gerando mudanças em várias áreas/departamentos. Como você acredita que a gestão ambiental pode ser inserida no debate do curso: de forma segmentada (cada área tem sua aplicação) ou de forma sistêmica (todo o curso é orientado pela gestão ambiental)?;

e) do ponto de vista organizacional, quais são as vantagens de se inserir a temática socioambiental nos objetivos, práticas e estratégias da empresa? Para responder a essa questão, sugere-se Barbieri (2016) e Vilela Junior e Demajorovic (2010).

No próximo tópico, há uma breve dis- cussão da literatura consoante com a discussão das questões abordadas nesta sessão.

\section{REFERENCIAL TEÓRICO}

Corcoran e Wals (2004) já afirmavam que a suposição da cultura humana tem sido que a beleza e a generosidade da Terra seriam transferidas por meio das gerações, e que o processo de educação iria transferir os valores, as habilidades e os conhecimentos para sobreviver e prosperar nos meios cultural e natural, sistemas dos quais fazemos parte. As universidades tiveram, no mundo moderno, uma posição central na definição da educação para essa tarefa. No entanto, certas ideias centrais, incorporadas no pensamento disciplinar e na prática dessas ideias, são cada vez mais problemáticas. Portanto, um desafio para o ensino superior é reconsiderar as disciplinas, práticas institucionais e também sua missão de, como instituição, explicar o desenvolvimento sustentável em termos das questões econômicas e sociais.

O conceito de Educação Ambiental (EA) tem, segundo Pereira (2009), sofrido modificações ao longo dos tempos. No início, representava um caráter naturalista e, hoje, significa um equilíbrio entre o meio ambiente e o homem, em busca da construção de um futuro planejado e vivido em uma lógica de desenvolvimento e progresso. Hoffman (1999) em seu discurso sobre a educação ambiental, no final da década de 1990, questionava se as escolas de negócios estavam capacitando os estudantes e fazendo-os pensar a respeito das questões ambientais que enfrentariam no futuro. E a resposta para esse questionamento era um significativo 'não', pois as disciplinas dos cursos não envolviam o tema como deveriam. O autor já acreditava que, sendo a responsabilidade social um aspecto incorporado às organizações, naquele momento, era imprescindível que o ensino superior em Administração também o fizesse.

Seguindo na mesma abordagem de Hoffman (1999), Walck (2009) acreditava que, até meados de 2003, relacionar a educação gerencial ao meio ambiente e investigar os impac- 
tos dos negócios sobre o meio ambiente ainda eram novidade na pesquisa em administração, enquanto outras áreas de estudo já estavam incorporando, rapidamente, as questões ambientais. Assim, a mudança cultural em direção ao meio ambiente e à sustentabilidade reflete-se nesta área acadêmica em todo o mundo, em que a infraestrutura está instalada para tornar o currículo voltado às ações gerenciais mais sustentáveis. Rohrich e Takahashl (2019) afirmam que o crescimento no número de publicações sobre o tema cresceu muito a partir de 2006.

Para Pereira (2009), a EA é direito de todos nós, e cabe a cada estado criar as condições necessárias para uma apropriada implementação, não ignorando as potencialidades da EA, bem como sua renovação curricular. Um dos desafios relevantes dos educadores é capacitar estudantes tecnicamente, mas também programar as mudanças necessárias com o intuito de se reduzir os problemas socioambientais (GONÇALVES-DIAS et al., 2009).

A universidade precisa ir além de fazer perguntas, para as quais ainda não se tem respostas e superar definitivamente a prática de apenas informar sobre os problemas ambientais, pois a simples informação sobre o tema é importante, mas, por si, só não desencadeará as mudanças necessárias ao desenvolvimento de competências para a ação (GUIMARÃES; TOMAZELLO, 2003, p. 16).

Duas condições precisam ser atendidas para a promoção do desenvolvimento sustentável no currículo das escolas de Administração:

a) uma condição para que os desafios da sustentabilidade consigam integrar eficientemente o ensino da administração; para isso, é preciso planejar como a sustentabilidade será implantada: por meio de estruturas já existentes ou com a criação de novas estruturas;

b) e a outra condição é relativa ao status de sustentabilidade em um contexto predominantemente disciplinar dos cursos de Administração (JACOBI; RAUFFLET; ARRUDA, 2011).

Foi por essas evidências e, tendo consciência da necessidade de mudança, que o Grupo de Gestão Ambiental, do qual a professora Ro- berta fazia parte, decidiu que era hora de rever os planos de ensino e a própria ementa do curso, a fim de inserir a educação ambiental e a gestão ambiental como norteadoras do debate central na formação dos estudantes daquela instituição.

$\mathrm{O}$ tema ambiental tem ganhado mais espaço hoje dentro das estruturas da universidade, pois, antigamente, a forma de organização dos departamentos, característica histórica na estrutura universitária, valorizava as especificidades e desprezava as posições pluralistas, o que dificultava essa discussão ampla sobre as questões ambientais. Por isso, muitas vezes, as propostas interdisciplinares ficavam sem um local que as recebessem (GUIMARÃES; TOMAZELLO, 2003).

Muitas são as publicações recentes que remetem à importância da formulação de estratégias e mudanças curriculares de projetos pedagógicos em prol do desenvolvimento sustentável, e o estudo da percepção dos estudantes em administração sobre sustentabilidade para ampliar o conhecimento e a conscientização dos estudantes nas organizações (SHARMA; KELLY, 2014; WU; SHEN, 2016; HILL; WANG, 2018; LEAL FILHO et al., 2018).

$\mathrm{Na}$ última década, muitos programas de graduação, pós-graduação e especialização têm inserido módulos, cursos e componentes de sustentabilidade em seus currículos. Mais especificamente no ensino da Administração, os temas relacionados à sustentabilidade têm-se multiplicado (JACOBI; RAUFFLET; ARRUDA, 2011). É importante destacar que a visão atual sobre desenvolvimento sustentável se baseia no conceito de Elkington (2001) sobre o Triple Bottom Line, ou seja, as três dimensões da sustentabilidade: econômico, ambiental e social. Essa abordagem, portanto, indica que as disciplinas do curso de Administração precisam envolver requisitos que atendam objetivos econômicos, sociais e ambientais para as Organizações, o Governo e a Sociedade.

Freire (2007) elucida que uma educação para a sustentabilidade implica uma perspectiva de uma nova orientação para a prática letiva, sobressaindo as aprendizagens ativas, experienciais, colaborativas e dirigidas para a resolução de problemas, seja em nível local, regional, seja 
em nível mundial. Para isso, torna-se necessária a introdução de práticas investigativas na formação também de professores, para que eles fiquem em sintonia com a necessidade de mudança cultural, a fim de promover a educação para a sustentabilidade.

No caso de ensino investigado, Roberta se dedica à pesquisa na área de sustentabilidade por meio de suas experiências de pesquisa nacional e internacional, que permitem a ela e aos outros professores do grupo de pesquisa compreender as questões mais relevantes quando se trata das dimensões ambiental, social e econômica e os dilemas e entraves experimentados dentro das organizações ao buscar a sustentabilidade em suas práticas.

A formação de professores leva as instituições de ensino superior não apenas a educar, mas, em especial, nos cursos na área de gestão, a formar futuras gerações para tomadas de decisão responsável, passando essas instituições a ter um papel importante na trajetória de um futuro global mais sustentável. Esse papel é exercido por meio de três componentes: " 1 . os espaços de formação, intercâmbio e educação; 2. os espaços de pesquisa e geração de ideias; e 3. as organizações per se, com orçamentos e processos de tomada de decisão." (JACOBI; RAUFFLET; ARRUDA, 2011, p. 28).

Acredita-se que é por meio do conhecimento que o indivíduo consciente muda sua "forma de se relacionar com o meio, de maneira a conservar os bens naturais para as gerações futuras e a trans- formar os construtos ambientais, historicamente elaborados pelo homem em uma sociedade mais justa." (ARAÚJO; BIZZO, 2005, p. 1).

A educação ambiental, em suas diversas possibilidades, abre um estimulante espaço para repensar práticas sociais e o papel dos professores como mediadores e transmissores de um conhecimento necessário para que os estudantes adquiram uma base adequada de compreensão essencial do meio ambiente global e local, da interdependência dos problemas e soluções, e da importância da responsabilidade de cada um para construir uma sociedade planetária mais equitativa e ambientalmente sustentável (JACOBI, 2003, p. 204).

Os métodos educativos sustentáveis "apontam para propostas pedagógicas centradas na criticidade dos sujeitos, com vistas à mudança de comportamento e atitudes, ao desenvolvimento da organização social e da participação coletiva." (JACOBI; RAUFFLET; ARRUDA, 2011, p. 28), implicando a mudança de percepção e de valores, construção e reconstrução, em um processo contínuo de novas leituras e interpretações, configurando possibilidades novas de ação.

A Carta de Belgrado, elaborada na Iugoslávia em 1975, em um encontro promovido pela UNESCO, já demonstrava a preocupação com os efeitos da atividade humana no meio ambiente e buscava chamar a atenção da sociedade com relação a seus compromissos para com a melhoria da qualidade de vida da população.

Quadro 4 - Diretrizes Básicas da Educação Ambiental segundo a Carta de Belgrado

\begin{tabular}{l}
$\begin{array}{l}\text { 1. A Educação Ambiental deve considerar o ambiente em sua totalidade - natural e criado pelo homem, } \\
\text { ecológico, econômico, tecnológico, social, legislativo, cultural e estético. }\end{array}$ \\
\hline 2. A Educação Ambiental deve ser um processo contínuo, permanente, tanto dentro como fora da escola. \\
\hline 3. A Educação Ambiental deve adotar um método interdisciplinar. \\
\hline A Educação Ambiental deve enfatizar a participação ativa na prevenção e solução dos problemas ambientais. \\
\hline $\begin{array}{l}\text { 4. A Educação Ambiental deve examinar as principais questões ambientais em uma perspectiva mundial, } \\
\text { considerando, ao mesmo tempo, as diferenças regionais. }\end{array}$ \\
\hline 5. A Educação Ambiental deve se basear nas condições ambientais atuais e futuras. \\
\hline 6. AEducação Ambiental deve examinar todo o desenvolvimento e crescimento a partir do ponto de vista ambiental. \\
\hline $\begin{array}{l}\text { 7. A Educação Ambiental deve promover o valor e a necessidade da cooperação em nível local, nacional } \\
\text { e internacional, na solução dos problemas ambientais. }\end{array}$
\end{tabular}

Fonte: (MEC, 2015). 
O quadro 4 mostra quais foram as Diretrizes Básicas dos Programas de Educação Ambiental estabelecidas pela Carta de Belgrado. Como resultado desse encontro, entendeu-se que a educação ambiental ajuda as pessoas e os grupos sociais a adquirirem as aptidões necessárias para resolver os problemas ambientais.

Deve-se ainda ressaltar a importância de que não basta elaborar políticas de curto prazo, mas preparar aqueles que serão responsáveis pelas decisões que serão tomadas e afetarão o futuro do planeta. Para Jabbour e Jabbour (2013), é possível promover a gestão ambiental em seu estágio proativo nas organizações, gerando mudanças em várias áreas/departamentos.

a) alta administração - dará suporte para a criação de uma cultura organizacional de valorização das questões ambientais;

b) gestão de recursos humanos - criará um alinhamento entre as práticas de gestão de pessoas e os objetivos ambientais;

c) gestão de tecnologia de informação/ sistemas de informação - oferecerá suporte à gestão dos dados e às informações ambientais;

d) gestão da produção/operações - área onde se geram os principais impactos ambientais; criará uma produção mais limpa e menos impactante;

e) gestão financeira - avaliará os indicadores financeiros e oportunidades de investimento, que estejam relacionados à gestão ambiental;

f) gestão de marketing - criará condições para a obtenção de vantagens competitivas, provenientes do marketing verde;

g) gestão da cadeia de suprimentos - incluirá os demais atores da cadeia em busca de melhorias ambientais;

h) gestão de pesquisa $\&$ desenvolvimento $(\mathrm{P} \& \mathrm{D})$ - buscará melhor aspectos para os produtos na ótica do que é ambientalmente adequado;

i) relações públicas/imprensa - responsável por comunicar entre as organizações e as partes interessadas o desem- penho ambiental dessas organizações.

A contribuição de recursos humanos à gestão ambiental pode ser estabelecida em parceria entre as áreas, caso necessite ser desenvolvida uma competência ambiental por alguma divisão mediante treinamento (JABBOUR; SANTOS, 2006). Em relação à produção e à gestão ambiental, os autores esclarecem que elas se integram quando há uma necessidade divisional que exige as duas especializações.

Entre os desafios para o avanço da sustentabilidade no curso de Administração, Jacobi, Raufflet e Arruda (2011, p. 42-45) propõem quatro caminhos: (1) da aprendizagem individual à aprendizagem coletiva - construindo comunidades de aprendizagem (grupo de pessoas que dividem as mesmas emoções, os valores e as crenças, e está ativamente engajado em aprender em conjunto e uns com os outros, por habituação); (2) educação para a sustentabilidade - na direção da aprendizagem social (alterar da lógica prescritiva, para uma visão que enfatize uma abordagem que transcenda fronteiras disciplinares); (3) integração do conhecimento: a sustentabilidade como janela de oportunidade nos cursos de Administração (redefinição do quadro de ensino/ aprendizagem); (4) além do tratamento gerencial: educando indivíduos responsáveis e comprometidos com a sustentabilidade (convite a repensar o papel do ensino da Administração em relação à educação de estudantes e futuros gestores).

No entanto, uma questão que ainda permanece em pauta é o conteúdo em termos de sustentabilidade a ser desenvolvido em sala de aula junto com os estudantes. Landrum e Ohsowski (2017) comentam que, em recente workshop realizado sobre sustentabilidade na grade curricular de cursos de ensino superior, a pergunta crítica na mente de cada participante era o que ensinar. Os participantes desejavam orientação sobre conteúdo específico. Essa observação também se aplica ao ensino da gestão empresarial sustentável. Nas experiências dos autores, os professores estão desenvolvendo conteúdo exclusivo para informar os estudantes, mas não há acordo sobre o que deve ser tra- 
tado nas disciplinas. Ao contrário de um curso introdutório em disciplinas de negócios, não há acordo geral sobre os recursos para o ensino da sustentabilidade em cursos na área de gestão. Assim, permanece a pergunta: o que deve ser ensinado aos estudantes para educá-los sobre tópicos de negócios sustentáveis?

A Década das Nações Unidas da Educação para o Desenvolvimento Sustentável 2005-2014 estimulou os países ao redor do mundo para a execução de medidas progressivas para integrar a sustentabilidade nos planos de educação, inclusive, no ensino superior. Entre tais iniciativas, destacam-se os Principles for Responsible Management Education (PRME) no campo da área de negócios. Em 2006, a Organização das Nações Unidas (ONU), juntamente com diretores e reitores de escolas de negócios de diversos países, divulgou seis princípios de educação responsável, apresentados no quadro 5. ração de disciplinas já existentes, promovendo a transversalidade da educação socioambiental nos cursos como um todo e, com isso, a formação socioambiental responsável dos egressos.

A adoção de princípios socioambientais em suas práticas e políticas traz benefícios não somente às organizações, mas também às escolas de gestão, a saber: as empresas que incorporam, em suas estratégias e atividades diárias, os valores de sustentabilidade e cidadania corporativa são os precursores de um processo de adaptação necessária ao mundo das organizações; as escolas de negócios e instituições de gestão relacionadas estão intimamente ligadas à comunidade em que servem: o mundo corporativo e seus stakeholders; os Princípios para a Educação Empresarial Responsável (PRME) são um chamado para incentivar e facilitar o progresso das escolas de negócios em larga escala para uma nova abordagem na educação

Quadro 5 - Princípios para a Educação Empresarial Responsável

Princípio 1 | Propósito: vamos desenvolver as capacidades dos estudantes para se tornarem futuros geradores de valor sustentável para os negócios e a sociedade em geral e trabalhar para uma economia global inclusiva e sustentável.

Princípio 2 | Valores: Nós vamos incorporar, em nossas atividades acadêmicas e currículos, os valores da responsabilidade social global como retratadas em iniciativas internacionais, como o Pacto Global das Nações Unidas.

Princípio 3 | Método: Vamos criar estruturas educacionais, materiais, processos e ambientes que possibilitem experiências eficazes de aprendizado para liderança responsável.

Princípio 4 | Pesquisa: Vamos engajar-nos em pesquisas conceituais e empíricas que avançam nossa compreensão sobre o papel, dinâmica e impacto de corporações na criação de valor social, ambiental e econômico sustentável.

Princípio 5 | Parceria: Vamos interagir com os gestores das corporações de negócios para ampliar nosso conhecimento sobre seus desafios na assunção de responsabilidades sociais e ambientais e explorar, conjuntamente, abordagens eficazes para enfrentar esses desafios.

Princípio 6 | Diálogo: Iremos facilitar e apoiar o diálogo e o debate entre educadores, estudantes, empresas, governos, consumidores, mídia, organizações da sociedade civil e outros grupos e partes interessadas em questões críticas relacionadas à responsabilidade social global e sustentabilidade.

Fonte: (PRME, 2012).

Os princípios listados auxiliam as escolas na implantação de uma educação voltada para a sustentabilidade, contribuindo para a formação socioambiental responsável dos gestores. Esses princípios precisam ser incorporados na estrutura pedagógica das faculdades, por meio da criação de novas práticas, novas disciplinas e alte- que atenda às novas necessidades e expectativas do mundo dos negócios e as exigências de uma nova geração de alunos com relação à sustentabilidade e à boa cidadania corporativa (SANTANA; AMUI; CEZARINO, 2014). 


\section{CONSIDERAÇÕES FINAIS}

Esta pesquisa trata de uma temática relevante para o ensino dos cursos na área de gestão: a educação ambiental e a gestão ambiental. A ideia do Caso de Ensino, que trata da história de Roberta e dos demais professores da faculdade em um interior de Minas Gerais, é debater sobre possibilidades de inserção do tema sustentabilidade dentro dos diversos eixos que compõem o ensino superior no país: ensino, pesquisa e extensão. Embora o debate sobre o tripé da sustentabilidade (econômico, social e ambiental) seja latente dentro das organizações, ainda é um desafio para os cursos de graduação, promover projetos pedagógicos com atividades multidisciplinares, para que o aprendizado seja sistêmico, assim como a gestão é na prática.

Conforme Leal Filho et al. (2018), a implementação de abordagens educacionais emergentes sobre o conteúdo curricular para o desenvolvimento sustentável pode ser considerada uma ferramenta para apoiar o aprendizado em sustentabilidade. A incorporação da educação em sustentabilidade nas atividades acadêmicas é promovida, especificamente, por meio do melhor entendimento das diferentes questões globais relacionadas ao desenvolvimento sustentável, como: pobreza extrema, direitos humanos, globalização, questões de igualdade, ética profissional e meio ambiente. Os benefícios dessa abordagem, vinculando a teoria com a prática, é que ela pode ajudar os alunos a criar links para o mundo real, encorajando-os a se considerar cidadãos globais e, assim, promover um senso de responsabilidade social global.

\section{REFERÊNCIAS}

ARAUJO, M. I. O.; BIZZO, N. O discurso da sustentabilidade, educação ambiental e a formação de professores de biologia. Enseñanza de las Ciencias, numero extra, VII Congreso, 2005. Disponível em: https://core.ac.uk/download/pdf/13303035.pdf. Acesso em: 24 jul. 2018.
BARBIERI, J. C. Gestão ambiental empresarial: conceitos, modelos e instrumentos. 4. ed. São Paulo: Saraiva, 2016.

CEZARINO, L. O. et al. Students' knowledge of sustainability issues in higher education. Latin American Journal of Management for Sustainable Development, v. 4, n. 1, p. 24-40, 2018 .

CORCORAN, P. B.; WALS, A. E. J. The problematics of sustainability in higher education: an introduction. In: CORCORAN, Peter Blaze; WALS, Arjen (ed.). Higher education and the challenge of sustainability: problematics, promise and practice. [S.l.: s.n.], 2004.

ELKINGTON, J. Canibais com garfo e faca. São Paulo: Makron Books, 2001.

FINDLER, F. et al. The impacts of higher education institutions on sustainable development: a review and conceptualization. International Journal of Sustainability in Higher Education, v. 20, n. 1, p. 23-38, 2019.

FREIRE, A. M. Educação para a sustentabilidade: implicações para o currículo escolar e para a formação de professores. Pesquisa em Educação Ambiental, v. 2, n. 1, p. 141-154, 2007.

GONÇALVES-DIAS, S. L. F. et al. Consciência Ambiental: um estudo exploratório sobre suas implicações para o ensino de Administração. RAE Eletrônica - Revista de Administração de Empresas FGV, v. 8, n. 1, 2009.

GUIMARÃES, S. S. M.; TOMAZELLO, M. G. C. A formação universitária para o ambiente: educação para sustentabilidade. Ambiente e Educação, v. 8, p. 55-71, 2003.

HILL, L. M.; WANG, D. Integrating sustainability learning outcomes into a university curriculum. International Journal of Sustainability in Higher Education, v. 19, n. 4, p. 
699-720, 2018.

HOFFMAN, A. J. Environmental Education in Business Schools. Environment, USA, p. 1e2. Jan./Feb.1999.

JABBOUR, A. B. L. S.; JABBOUR, J. C. Gestão ambiental nas organizações: fundamentos e tendências. São Paulo: Atlas, 2013.

JABBOUR, C. J. C.; SANTOS, F. C. A. Evolução da gestão ambiental na empresa: uma taxonomia integrada à gestão da produção e de recursos humanos. Gestão \& Produção, v. 13, n. 3, p. 435-448, set./dez. 2006.

JACOBI, P. Educação ambiental, cidadania e sustentabilidade. Cadernos de Pesquisa, $n$. 118, p. 189-205, mar. 2003.

JACOBI, P. R.; RAUFFLET, E.; ARRUDA, M. P. de. Educação para a sustentabilidade nos cursos de administração: reflexão sobre paradigmas e práticas. Rev. Adm. Mackenzie, v. 12, n. 13, p. 21-50, maio/jun. 2011.

LADEIRA, W. J.; SANTINI, F. O.; ARAUJO, C. F. Práticas sustentáveis nas instituições de ensino superior: uma proposta de taxonomia baseada na percepção ambiental dos alunos do curso de administração. Administração: Ensino e Pesquisa, v. 13, n. 4, p. 735-761, 2012.

LANDRUM, N. E.; OHSOWSKI, B. Content trends in sustainable business education: an analysis of introductory courses in the USA. International Journal of Sustainability in Higher Education, v. 18, n. 3, p. 385-414, 2017.

LEAL FILHO, W. et al. The role of transformation in learning and education for sustainability. Journal of Cleaner Production, v. 199, p. 286-295, 2018

PEREIRA, R. B. C. T. Educação ambiental no ensino básico e secundário: concepções de professores e análise de manuais escolares. 2009. 338 f. Tese (Doutorado) - Universidade do Minho - Instituto de Estudos da Criança, Portugal, 2009.

PRINCIPLES FOR RESPONSIBLE MANAGEMENT EDUCATION (PRME). Six Principles. 2012. Disponível em: http://www. unprme.org/about-prme/the-six-principles.php. Acesso em: 24 jul. 2018.

ROHRICH, S. S.; TAKAHASHI, A. R. W. Sustentabilidade ambiental em instituições de Ensino Superior, um estudo bibliométrico sobre as publicações nacionais. Gestão \& Produção, v. 26, n. 2, 2019.

SANTANA, I. P.; AMUI, L. B. L.; CEZARINO, L. O. Formação Gerencial e o Perfil do Gestor para a Sustentabilidade. In: ENCONTRO INTERNACIONAL SOBRE GESTÃO AMBIENTAL, 16., 2014, São Paulo. Anais [...]. São Paulo: Engema, 2014.

SHARMA, U.; KELLY, M. Students' perceptions of education for sustainable development in the accounting and business curriculum at a business school in New Zealand. Meditari Accouting Research, v. 22, n. 2, p. 130-148, 2014.

VILELA JUNIOR, A.; DEMAJOROVIC, J. Modelos e ferramentas de gestão ambiental: desafios e perspectivas para as organizações. 2 . ed. São Paulo: Editora Senac, 2010.

WALCK, C. Integrating Sustainability into management education. Journal of Management Education, v. 33, n. 3, p. 384-390, 2009.

WU, YC. J.; CHEN, J. P. Higher education for sustainable development: a systematic review. International Journal of Sustainability in Higher Education, v. 17, n. 5, p. 633-651, 2016. 